\title{
Pyricularia grisea CAUSANDO LESÕES NECRÓTICAS EM FOLHAS DE BANANEIRA
}

\author{
DINALDO R. TRINDADE, LUIZ S. POLTRONIERI, FERNANDO C. ALBUQUERQUE \\ \& ANTÔNIO JOSÉ E. A. MENEZES
}

\author{
Embrapa Amazônia Oriental, Cx. Postal 48, CEP 66095-100, Belém, PA, e-mail: dinaldo@ @patu.embrapa.br
}

(Aceito para publicação em 18/04/2002)

Autor para correspondência: Dinaldo R. Trindade

ABSTRACT
Pyricularia grisea causing leaf spots in banana produced by micropropagation
Banana (Musa sp.) seedlings produced by by Pyricularia grisea causing necrotic leaf spot limiting the
micropropagation in the aclimatation stage have been infected $\begin{aligned} & \text { growth of the explants. }\end{aligned}$

Em razão da ocorrência da doença conhecida como sigatoka negra (Mycosphaerella fijiensis Morelet) no Pará, está sendo recomendado utilizar em novos plantios de bananeira (Musa sp.) cultivares resistentes a essa doença. Como a demanda é muito grande, o material genético está sendo multiplicado por micropropagação. $\mathrm{Na}$ fase de aclimatação, plantas da cultivar Thap Maeo com dois meses de idade estão apresentando nas folhas, lesões necróticas de coloração parda medindo de 0,3 a 1,2 cm de diâmetro, que mais tarde coalescem culminando com a seca total da folha e morte da planta (Figura 1-A). A partir de amostras de tecidos com lesões necróticas encaminhadas ao laboratório de fitopatologia da Embrapa Amazônia Oriental, foi feito isolamento em meio de cultura BDA, com incubação à temperatura ambiente de laboratório e na presença de luz. Nessas condições obteve-se um fungo que produziu conidióforos longos, delgados e simples, conídios em formato semelhante a pêra, com extremidade formando um bico e alguns conídios presos ao conidióforo pela base alargada, hialinos com até três células (Figura 1-B). De acordo com a literatura, essas características indicam tratar-se do fungo Pyricularia grisea (Cooke) Sacc. cuja fase teleomorfa corresponde a Magnaporthe grisea (Hebert) Barr. Há registros de ocorrência dessa doença em frutos e folhas de bananeira na América Central (Guyon, M. Fruits 25:685-691. 1970; Meredith, D.S. Ann. Appl. Biol. 52:453-463. 1963) e no Brasil (Cordeiro \& Kimati. Manual de Fitopatologia. v.2. 1997; Cordeiro \& Matos. In: Banana- Fitossanidade. Embrapa Comunicação para Transferência de tecnologia. Frutas do Brasil, v.8. 2000). Foram feitos testes de patogenicidade em folhas destacadas de bananeira mantidas em câmara úmida e em plantas sadias originadas de micropropagação mantidas em telado, pertencentes à cultivar Thap Maeo. Em ambas as situações, após cerca de 15 dias, houve a reprodução dos sintomas confirmando a patogenicidade do isolado.

Este é o primeiro relato de ocorrência de $P$. grisea em bananeiras no estado do Pará.

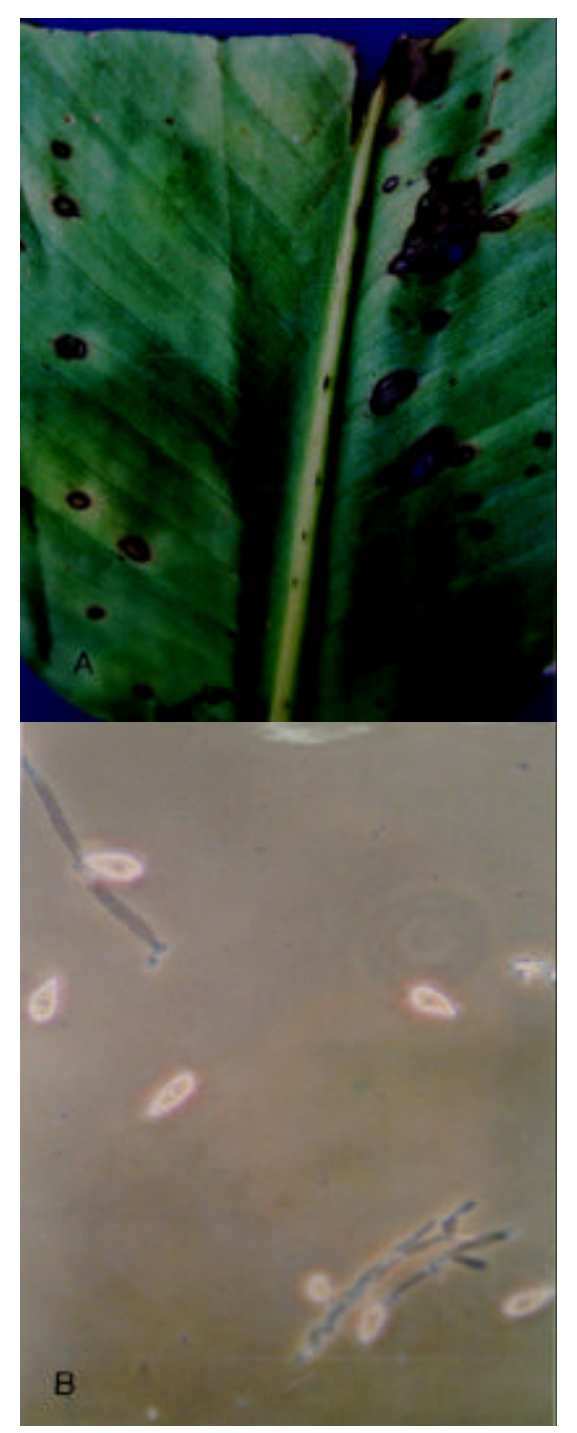

FIG. 1 - A- Lesões necróticas causadas por Pyricularia grisea em folhas de bananeira (Musa sp.); Bconídios de $P$. grisea 